\title{
Immune Abnormalities in Diabetic Patients Not Requiring Insulin at Diagnosis
}

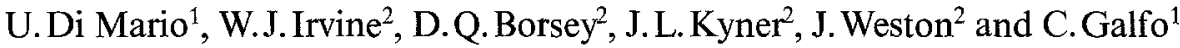 \\ ${ }^{1}$ Cattedra di Endocrinologia, Università La Sapienza, Rome, Italy, and \\ ${ }^{2}$ Endocrine Unit/Immunology Laboratories (Medicine) and Diabetic Department, Royal Infirmary, Edinburgh, UK
}

Summary. Islet cell antibodies (ICA), complement fixing islet cell antibodies, immune complexes and thyro-gastric autoantibodies were studied in newly diagnosed diabetic patients not requiring insulin at diagnosis. Particular attention was focussed on that minority of patients who are initially treated with diet or oral agents but show ICA in their serum. One hundred and six non-insulin-requiring patients were studied at clinical diagnosis. Seventeen who had ICA in their serum were compared with a control group of 89 who did not. The 17 ICA-positive diabetic patients were followed serologically for approximately 1 year from diagnosis. Patients were followed clinically for 3 years. Forty-seven percent of ICA-positive and $19 \%$ of ICA-negative patients had immune complexes in their serum. Eleven of the 17 ICA-positive patients also had serum complement fixing islet cell antibodies. Thyro-gastric anti- bodies were found in $29 \%$ of ICA-positive and $18 \%$ of ICA-negative diabetic patients. ICA, complement fixing antibody and immune complex positivity declined with time. Ten of the 17 ICA-positive and two of the 89 ICA-negative patients required insulin within 3 years of diagnosis. There was a positive trend for the presence of complement fixing islet cell antibodies at diagnosis to be associated with the early development of insulin dependency. The type of diabetes in ICA-positive patients not requiring insulin at diagnosis has strong immunological and clinical similarities to classical Type 1 (insulin-dependent) diabetes.

Key words: Type 1 diabetes, Type 2 diabetes, islet cell antibodies, complement fixing islet cell antibodies, immune complexes, thyro-gastric autoantibodies.
Circulating immune complexes (AgAb) have been reported to be present in higher levels in newly diagnosed Type 1 (insulin-dependent) diabetic patients and to be correlated with islet cell antibodies (ICA) at and shortly after diagnosis [1-3]. These circulating complexes may have a pathogenic role or simply reflect the presence of ketosis and metabolic derangement in the early phases of clinical diabetes, which could modify the dynamics of formation and clearance of $\mathrm{AgAb}$ [4].

In this study, we investigated the presence of soluble $\mathrm{AgAb}$ in diabetic patients who did not require insulin at the time of clinical diagnosis. Particular attention was focussed on the minority who did not have ketonuria but showed ICA in the serum at diagnosis. In this relatively uncommon group of patients, ICA, complement fixing islet cell antibodies (CF-ICA) and $\mathrm{AgAb}$ were tested at diagnosis and at regular intervals thereafter. Clinical and subclinical associations with other autoimmune phenomena were studied also.

Our aims were to highlight the presence of $\mathrm{AgAb}$ in patients who were ICA-positive but not ketotic, the modifications with time of ICA, CF-ICA and AgAb and the correlation between the presence of ICA, CF-
ICA or $\mathrm{AgAb}$ at diagnosis and in the following months with the tendency to progress to insulin dependency.

\section{Subjects and Methods}

\section{Subjects}

Over a period of a year most patients newly diagnosed at a few Edinburgh Diabetic Clinics as Type 2 (non-insulin dependent) diabetic subjects, according to the National Diabetes Data Group Classification [5], were tested for ICA at their first attendance. Two hundred and sixty patients were tested of whom 106 were included in this study: all those who were ICA-positive (17), together with 89 who were selected randomly from the newly diagnosed ICA-negative diabetic patients.

In the ICA-positive group, there were five males and 12 females with a mean age at diagnosis of $55.4 \pm 16.1$ years. In the ICA-negative group, 42 were male and 47 were female and the mean age at diagnosis was $61.6 \pm 12$ years. Two of the 17 ICA-positive and two of the 89 ICA-negative patients had other associated autoimmune diseases (Hashimoto's thyroiditis, pernicious anaemia and primary hypothyroidism). Almost all the 17 ICA-positive patients could be considered to have Type 2 a diabetes [5], the median of the ideal body weight being $98.5 \%$. No other substantial difference in the symptoms preceding diagnosis or in the clinical and metabolic signs at the onset of overt diabetes was noticed between ICA-positive and ICA-negative patients. 
Since there are no reports of ICA-negative diabetic patients later becoming positive, we concentrated our study on the 17 initially ICApositive patients; they were followed serologically at regular intervals for approximately 1 year from diagnosis and serum antibodies were tested twice, once between 2 and 4 months and again 10 or more months after diagnosis.

This research was part of a more general study, so that the clinicians did not know the result of the ICA test, at least in the first months, and in any case ICA status was not among the parameters taken into account when the decision to put patients on insulin was taken.

\section{Methods}

$\mathrm{AgAb}$ were evaluated by the solid phase Clq radioimmunoassay according to Hay et al. [6], with minor modifications. Details of the technique used, the limit of positivity, the expression of results and the reproducibility of the test have been published previously $[1,7]$. ICA, thyroid cytoplasmic and gastric parietal cell antibodies were determined by indirect immunofluorescence using fresh frozen cryostat sections [8,9]. CF-ICA were evaluated with the addition of fresh normal serum as the source of complement and fluorescein conjugated anti-C3 antibody [10].

Statistical evaluation was done by $\chi^{2}$ test, with Yates' correction when appropriate, and by the two tailed Cox's test for trends in proportions when indicated.

\section{Results}

\section{Islet Cell Antibodies}

In the ICA-positive patients, ICA were still present in 14 out of 17 between 2 and 4 months after diagnosis and in 10 out of 16 after 1 year or more of clinical diabetes (Fig. 1).

\section{Immune Complexes}

$\mathrm{AgAb}$ were found in eight of the 17 ICA-positive diabetic patients $(p<0.01$ versus normal subjects) and in 16 of the 89 ICA-negative patients (NS versus normal subjects, $p<0.02$ versus ICA-positive patients), both groups being studied at diagnosis.

\section{Complement Fixing Islet Cell Antibodies}

CF-ICA were found in 11 of the 17 ICA-positive diabetic patients. At the end of the first 3 months, ten patients were positive; five were still positive 10 months or more from diagnosis (Fig. 1). None of the patients who were CF-ICA-negative at diagnosis became CF-ICA-positive with time.

\section{Thyro-gastric Antibodies}

Autoantibodies to thyroid or to gastric parietal cells, studied in all the patients at diagnosis, were found in five of the 17 ICA-positive and in 16 of the 89 ICA-negative diabetic patients (NS).

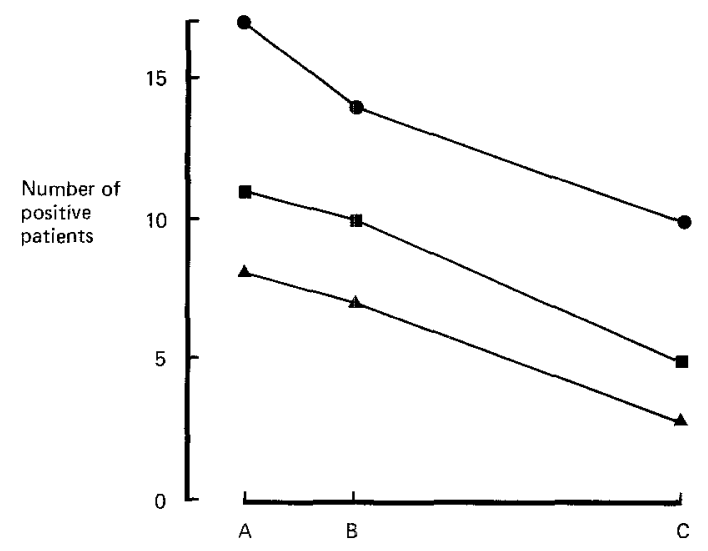

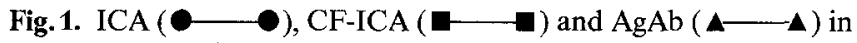
the 17 ICA-positive diabetic patients initially treated without insulin, at diagnosis (A), between the second and the fourth month of the disease (B), and after 10 months or more of clinical diabetes (C)

\section{ICA, CF-ICA, AgAb and Clinical Tendency to Progress to Insulin Dependency}

Ten of the 17 ICA-positive and two of the 89 ICA-negative diabetic patients required insulin within 3 years of diagnosis $(p<0.0001)$, either because of the presence of ketonuria and/or because of a metabolic derangement (glycaemia constantly $>12 \mathrm{mmol} / \mathrm{l}$ ) non-controllable with other therapy. When the patients were divided according to tendency to progress to insulin dependency (Fig. 2), five were still on oral hypoglycaemic agents more than 3 years from diagnosis, six went on to insulin after 20 months of clinical diabetes, four between 6 and 10 months and two died from vascular complications after 5 and 21 months, respectively. There was a significant trend for the presence of CF-ICA at diagnosis to be associated with earlier development of insulin dependency $(p<0.05)$. The occurrence of $\mathrm{AgAb}$ and of thyrogastric antibodies were not correlated with the tendency to progress to insulin dependency.

\section{Discussion}

While an increased prevalence of immune complexes has been shown in the serum at diagnosis of Type 1 diabetes [1-3], this is not the case here where a substantial number of randomly selected Type 2 diabetic patients have been studied at diagnosis and compared with control subjects. However, the present study demonstrates that the prevalence of $\mathrm{AgAb}$ is increased in the minority of diabetic patients who have ICA in the serum but do not require insulin at diagnosis or during the first months of the disease. A correlation between serum Ag$\mathrm{Ab}$ and ICA has been demonstrated also in Type 1 diabetic patients close to diagnosis [1-3] and in those Type 1 diabetic patients in whom ICA persists for some years [11]. The correlation between serum ICA and Ag$\mathrm{Ab}$ suggests that islet cell antigen-antibody complexes may be part of the $\mathrm{AgAb}$ detected in the subjects. 


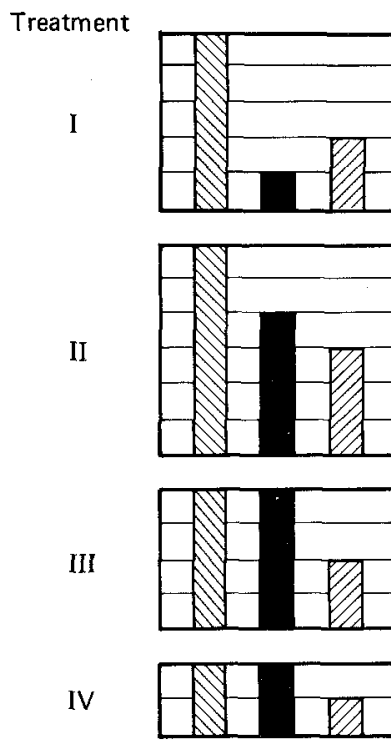

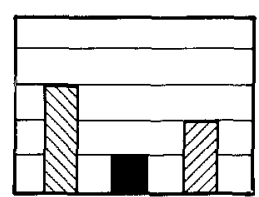
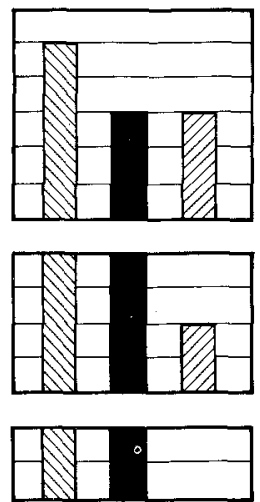

B
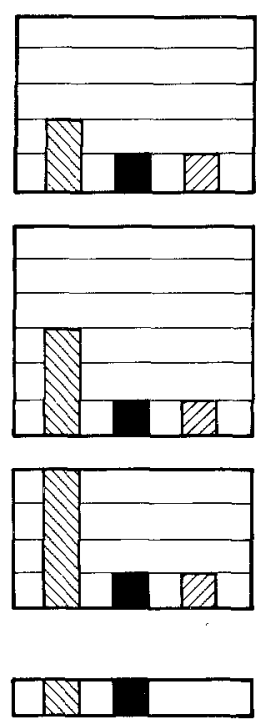

C
Fig. 2. ICA ( $\square$, CF-ICA ( $), \operatorname{AgAb}(\square)$ and tendency to progress to insulin dependency. The horizontal lines within the rectangular frames indicate the number of patients. Group 1 patients $(n=5)$ were still on oral hypoglycaemic agents 3 years from clinical diagnosis, Group $2(n=6)$ required insulin between 20 and 36 months from diagnosis, Group $3(n=4)$ needed insulin within 10 months and the two Group 4 patients died during the follow-up study. A, B and C as in Figure 1
Whether $\mathrm{AgAb}$ are involved in islet cell damage in these patients has not yet been established, but they could be involved in serum cytotoxic activity or they could interact in several ways with cells which have receptors for the $\mathrm{Fc}$ portion of immunoglobulins or for the third component of complement [12]. As our ICA-positive diabetic patients not requiring insulin at diagnosis were not ketotic, severe metabolic derangement would not seem to be a major factor in the development of serum $\mathrm{AgAb}$ in these subjects. Furthermore, hyperglycaemia is unlikely to be responsible as an increased presence of $\mathrm{Ag}$ $\mathrm{Ab}$ was seen in ICA-positive non-insulin diabetic patients but not in the majority of patients with Type 2 diabetes.

The present study demonstrates that a small proportion of apparent Type 2 diabetic patients show the same immunopathological phenomena that occur in classical Type 1 diabetes at diagnosis; i. e. ICA, CF-ICA and Ag$\mathrm{Ab}$. It has been demonstrated previously that the presence of serum ICA in diabetic patients initially treated with diet and/or oral hypoglycaemic agents is a useful marker for predicting subsequent insulin dependency [13]. The findings of this study suggest that when serum CF-ICA are present, the development of insulin dependency tends to occur earlier. A similar predictive value for CF-ICA was recently shown by other workers in different situations, i.e. Type 1 diabetes, relatives of patients with Type 1 diabetes or patients with autoimmune disorders $[10,14,15]$.

ICA-positive diabetic patients, not requiring insulin at diagnosis, who may also have CF-ICA and $\mathrm{AgAb}$ at diagnosis, clearly do not fit logically into the broad clinical subdivision of the majority of idiopathic diabetic patients according to the presence or absence of insulin dependency [14]. At clinical diagnosis, Type 1 diabetic patients are ketosis prone and have islet cell autoimmunity. Type 2 diabetic patients classically have neither of these characteristics. The small group of subjects included in the present study showed no ketonuria and did not require insulin at diagnosis but had evidence of islet cell autoimmunity and tended to progress to insulin dependency. As argued previously [16], the type of diabetes in ICA-positive non-insulin requiring diabetic patients should be regarded as a subgroup of Type 1 diabetes, probably representing a stage earlier in the same disease process (or group of disease processes) that tends to culminate in classical Type 1 diabetes.

Acknowledgements. The authors wish to thank Mr. C. Tiberti for his skilful technical work and Miss F. Craik and Miss P. Henley for their excellent secretarial assistance.

\section{References}

1. Irvine WJ, Di Mario U, Guy K, Feek CM, Gray RS, Duncan LJP (1978) Immune complexes in newly diagnosed insulin dependent (Type 1) diabetics. J Clin Lab Immunol 1: 183-186

2. Fairchild RF, Kyner JL, Abbou NI (1982) Specific immunoregulation abnormality in insulin dependent diabetes mellitus. J Lab Clin Med 99: 175-186

3. Borsey DQ, Di Mario U, Irvine WJ, Gray RS, Weston J, Peutherer J, Duncan LJP (1983) Humoral immunity in Type 1 diabetes mellitus: a prospective study. J Clin Lab Immunol 11:9-15

4. Mannik M, Haakenstad AO, Arend WP (1974) The fate and detection of circulating immune complexes. In: Brent $\mathrm{L}$, Holborow $J$ (eds) Progress in immunology II, vol 5. North Holland, Amsterdam, pp 91-101

5. National Diabetes Data Group (1979) Classification and diagnosis of diabetes mellitus and other categories of glucose intolerance. Diabetes 28: 1039-1057

6. Hay FC, Nineham LJ, Roitt IM (1976) Routine assay for the detection of immune complexes of known immunoglobulin class using solid phase Clq. Clin Exp Immunol 24: 396-400

7. Andreani D, Di Mario U, Ventriglia L, Galfo C, Iavicoli M (1982) Circulating immune complexes in diabetics with severe microangiopathy. Acta Endocrinol 99: 239-244

8. Bottazzo GF, Florin-Christensen A, Doniach D (1974) Islet cell antibodies in diabetes mellitus with autoimmune polyendocrine deficiencies. Lancet 2:1279-1282 
9. MacCuish AC, Irvine WJ, Barnes EW, Duncan LJP (1974) Antibodies to pancreatic islet cells in insulin-dependent diabetics with coexistent autoimmune disease. Lancet 2:1529-1531

10. Bottazzo GF, Dean BM, Gorsuch AN, Cudworth AG, Doniach D (1980) Complement fixing islet cell antibodies in Type 1 diabetes: possible monitors of active beta-cell damage. Lancet 1:668-672

11. Irvine WJ, Di Mario U, Guy K, Borsey DQ (1980) Immune complexes in Type 1 diabetes with and without persistent islet cell antibody. J Clin Lab Immunol 4: 87-89

12. WHO Scientific Group Report (1977) The role of immune complexes in disease. WHO, Geneva, No.6

13. Irvine WJ, McCallum CJ, Gray RS, Duncan LJP (1977) Clinical and pathogenic significance of pancreatic islet cell antibodies in diabetics treated with oral hypoglycaemic agents. Lancet 1: 1025-1027

14. Gorsuch AN, Lister J, Dean BM, Spencer KM, McNally JM, Bottazzo GF, Cudworth AG (1981) Evidence for a long prediabetic period in Type 1 (insulin dependent) diabetes mellitus. Lancet 2: 1363-1365

15. Betterle C, Caretto A, Tiengo A, Trevison A (1980) Complement fixing islet cell antibodies in Type 1 diabetes in susceptible patients with autoimmune diseases. Lancet 1: 1418-1419

16. Irvine WJ (1977) Classification of idiopathic diabetes. Lancet 1 : $638-642$

Received: 11 October 1982

and in revised form: 15 June 1983

Dr. U. Di Mario

Clinica Medica 2

Policlinico Umberto I

I-00161 Roma

Italy 